ORIGINAL PAPERS

\$1. 研究 $の$ 目的

常王における気体の粘度の推算式としては， Licht, Stechert の式1), Hirschfelder の式2), があり，ま 推算法としては，Uyehara-Watson の方法324がる がこれらはいずれる有機化合物では $130^{\circ} \mathrm{C}$ 以上になる と相当の誤差を生じ，さらに简温では数 $10 \%$ の誤差を 生じて到底使用にたえないことを発見した。また前の二 者の式では後述の会合効果を示すガスには使用できな

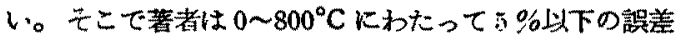
をむつ諸種の推算式を得んと志し一心圭て目的を迋する ことができた。本研究はその一端としておこなったもの である。周知のことく対闪状態の原理を使用すれば，常 区の任意の温度の気体粘度 $\mu$ は $\mu=\mu_{c}^{*} \times f\left(T_{r}\right)$ であ

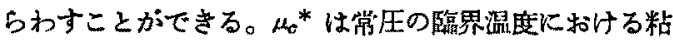

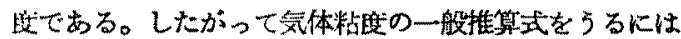
ぜとも $\mu_{c}^{*}$ の推賏式を必要とするか，本研究の目的 はこの $\mu_{c}^{*}$ の推算式をらるにあった。

\section{\$2. $\mu_{c}^{*} \oslash$ 推算式}

臨界状態に和忛る気体の粘度の推算式としては, Licht Stechert の次元解析比もとつく

$$
\mu_{c}=7.70 \times 10^{-6}\left(P_{c}^{4} \cdot M^{3} / T_{c}\right)^{1 / 6^{\prime}}
$$

があり，また $\mu_{c}^{*}$ の推算式としては, Licht-Stechert の常圧における気体粘度の推算式〉て $T_{r}=1$ とおいた 场合の

$$
\mu_{c}^{*}=3.5 \times 10^{-6}\left(P_{c} \cdot M^{3} / T_{c}\right)^{x / 6}
$$

がある

しかし後速の上うに，水とか $\mathrm{NH}_{3}$ のことく，臨界状 態で会合しているものとみられるガスおよび臨界温底 $t_{c}$ が $190^{\circ} \mathrm{C}$ 以上の有阵ガスに対しては，(2）式の定数 $K^{\prime}=3.5 \times 10^{-6}$ が適切でないことをみいたした。るこ で整者はこれらのガスに対して，いかなる $K$ をえらふ ベきであるかについて検討した。

著者は次元解析によって, Licht-Stechert の式を少し く改良したるのと考えら机る次式を淕集した。

$$
\mu_{c}=K_{c}\left(P^{3} c \cdot d_{c} M^{2}\right)^{1 / 6} N^{-1 / 3}
$$

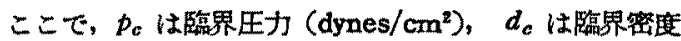
$\left(\mathrm{g} / \mathrm{cm}^{3}\right) ， M$ はグラム分子量， $N$ はフボガド口数であ

(1) 昭和 29 年 11 月 25 日受理

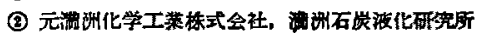

$\eta ， K_{c}$ は無次元定数である。

臨界压を気压临应の $P_{c}$ であらわし， $N=6.023 \times 10^{2}$ を代入すると

$$
\mu_{c}=K_{c}\left(P_{c}^{3} \cdot d_{c} \cdot M^{2}\right)^{1 / 0} \times 1.192 \times 10^{-5}
$$

ここで $P_{e} V_{c}=R_{c} T_{c}\left(V_{c}\right.$ は臨界容桠 $\left.l / \mathrm{moi}\right)$ とする と, $d_{G}=M / V_{c} \cdot 10^{3}$ であるから，これらを (3) 式に入 れると

$$
\mu_{c}=K_{c}\left(P_{c} d M^{3} / R_{c} T_{c}\right)^{1 / 6} \times 0.377 \times 10^{-5}
$$

を5各。

$\mu_{c}^{*}=\mu_{c} \cdot f\left(P_{r}\right)$ であるから，いま $f\left(P_{r}\right) \cdot K_{c}=K$ な る関係があるとすると， $\mu_{c}^{*}$ をあらわす式は

$$
\begin{aligned}
& \mu_{c}{ }^{*}=K\left(P_{c}{ }^{3} \cdot d_{c} \cdot M^{2}\right)^{1 / 6} \times 1.192 \times 10^{-5} \ldots \text { c.g.s }(5) \\
& \mu_{c}{ }^{*}=K\left(P_{c} \cdot M^{3} / R_{c} \cdot T_{c}\right)^{1 / 6} \times 0.377 \times 10^{-5} \cdots \text { c.g.s }
\end{aligned}
$$

でからわされる。

$d_{c}$ 不明の場合は，非会合ガスに対しては近似的に, $d_{c} \div 3.66 P_{c} M / R T_{e}$ を用いてよい。たたし $R$ は気体 定数。

(2) 式と，(6)，(6) 式を比較すればすぐ分るよ 5 に， 焎者の式は Licht-Stechert $\sigma(\mathrm{M})$ 式と本質的には全く 同して，ただ(侙では $T_{c}$ の代りにd を朋い，Licht Stechert の（2）式ては各ガスによって翼なる $R_{c}$ を定 数 $3.5 \times 10^{-6}$ の中に含ませているのに対し，(6) 式では これを $K$ の中に含ませず別にとりだしている点が異っ ているのみである。

以下各ガス群に対して，いがなる $K$ をえらんたがよ いかを，臨界定数の一つ少なくてすむ（5)式を用いてし らヘてみた。

\section{§ 3. $\boldsymbol{K}$ の決定已使用式}

既知の $\mu_{c}^{*}, P_{c}, M$ の值を用いて，29 種の気体につ いて（5）式より $K$ 考計算した。本報文の計算に用いた

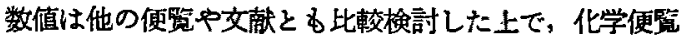
(昭和 27 年丸羓) の值を使用した。若千 Perry's Handbook，および他の交献より採用したものもある。Kの 計算結果 ( $K_{\text {obs }}$ ) Table 1 に示す。表よりみられる よ5KKの值が 0.48 に近いるの 0.5 以上となる の, 0.48 よりかり小さいものの三つに分けることがた きる。 $K$ の值を検討した結果，各ガスをその臨界温度 $t_{c}$ と，次の $\varphi$ の值によって分類しうることが分った。 
Table 1 Critical values of gases and calculated values of $K$ ( $K_{\mathrm{obs}}$ )

by formula (5), and deviation of $K_{\text {obs }}$ from mean value $K$

\begin{tabular}{|c|c|c|c|c|c|c|c|c|c|c|c|}
\hline & $\begin{array}{c}\text { gas } \\
\text { group }\end{array}$ & bas & $\left({ }^{t} c\right)$ & $\varphi$ & $\left(10-a_{c}^{a}{ }_{\text {poise }}^{*}\right)$ & $\underset{\text { (atmo }}{P_{a}}$ & $\begin{array}{c}d_{n} \\
(\mathrm{~g} / \infty)\end{array}$ & $E_{c}^{3} d_{c} M^{2}$ & $K_{\text {obs }}$ & $K$ & $\begin{array}{c}\text { error } \\
(\%)\end{array}$ \\
\hline & Ia & $\mathrm{CH}_{4}$ & -82.5 & 3.45 & 72.3 & 45.7 & 0.162 & 12.59 & 0.482 & 0.480 & 0.42 \\
\hline & $"$ & $\mathrm{C}_{2} \mathrm{H}_{6}$ & 35 & 3.60 & 96.5 & 49 & 0.21 & 16.80 & 0.482 & 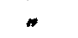 & 0.42 \\
\hline & $"$ & $\mathrm{C}_{9} \mathrm{H}_{8}$ & 96.8 & 3.70 & 102.7 & 42 & 0.226 & 17.80 & 0.484 & 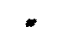 & 0.83 \\
\hline & $"$ & $\mathrm{SO}_{3}$ & 157.3 & 3.71 & 189.1 & 77.8 & 0.524 & 31.69 & 0.500 & $*$ & 4.16 \\
\hline & $"$ & $\mathrm{CO}_{2}$ & 31.0 & 3.57 & 150.3 & 73 & 0.46 & 26.50 & 0.476 & $n$ & -0.83 \\
\hline & $*$ & $\mathrm{Cl}_{2}$ & 144 & 3.63 & 186.5 & 76.1 & 0.573 & 32.91 & 0.475 & $"$ & -1.04 \\
\hline & $"$ & $\mathrm{~N}_{3} \mathrm{O}$ & 36.5 & 3.71 & 150.6 & 71.6 & 0.46 & 26.25 & 0.481 & $\Rightarrow$ & 0.21 \\
\hline & $"$ & $\mathrm{Xe}$ & 16.6 & 3.58 & 220.9 & 58.2 & 1.15 & 39.69 & 0.467 & $*$ & -2.71 \\
\hline & " & $\mathbf{H B r}$ & 90 & 3.54 & 227.6 & 84 & 0.807 & 38.24 & 0.499 & $"$ & 3.96 \\
\hline & $"$ & $\mathrm{C}_{2} \mathrm{H}_{2}$ & 35.7 & 3.65 & 106.7 & 61.6 & 0.231 & 18.22 & 0.491 & $"$ & 2.29 \\
\hline & " & $\mathrm{C}_{2} \mathrm{H}_{4}$ & 9.5 & 3.52 & 97.3 & 50.7 & 0.216 & 16.76 & 0.487 & $"$ & 1.46 \\
\hline & $\omega$ & $\mathrm{CH}_{s} \mathrm{OCH}_{3}$ & 126.9 & 3.71 & 120.2 & 52.0 & 0.271 & 20.80 & 0.185 & 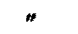 & 1.04 \\
\hline & $"$ & $\mathrm{CH}_{3} \mathrm{Cl}$ & 143.1 & 3.80 & 141.9 & 65.9 & 0.37 & 25.42 & 0.469 & $"$ & -2.29 \\
\hline & I b & $\mathrm{HCl}$ & 51,4 & 5.01 & 158.7 & 83 & 0.61 & 27.82 & 0.479 & $*$ & -0.21 \\
\hline & $\mathbf{I} \mathbf{c}$ & $\mathbf{N H}_{3}$ & 132.4 & 4.12 & 139.6 & 111.5 & 0.235 & 21.34 & 0.549 & 0.480 & 14.39 \\
\hline & $"$ & $n-\mathrm{C}_{4} \mathrm{H}_{10}$ & 152.0 & 3.91 & 107.1 & 34.5 & 0.225 & 17.74 & 0.506 & $"$ & 5.42 \\
\hline & IIC & $\mathrm{H}_{2} \mathrm{O}$ & 374.2 & 4.46 & 226.2 & 217.5 & 0.329 & 32.12 & 0.590 & $*$ & 22.9 \\
\hline & II a & $\mathrm{C}_{2} \mathrm{H}_{5} \mathrm{OC}_{2} \mathrm{H}_{5}$ & 193.8 & 3.86 & 103.5 & 35.5 & 0.265 & 20.05 & 0.433 & 0.422 & 2.61 \\
\hline & $"$ & $n-\mathrm{C}_{5} \mathrm{H}_{12}$ & 197 & 3.75 & 95.2 & 33.0 & 0.232 & 18.75 & 0.426 & $*$ & 0.95 \\
\hline & $"$ & $n-\mathrm{C}_{6} \mathrm{H}_{14}$ & 234.8 & 3.82 & 94.6 & 29.6 & 0.234 & 18.84 & 0.421 & $"$ & -0.24 \\
\hline & $"$ & $n-\mathrm{C}_{7} \mathrm{H}_{18}$ & 266.5 & 3.86 & 103.9 & 26.8 & 0.234 & 18.88 & 0.462 & 0.458 & 0.87 \\
\hline & $"$ & $n-\mathrm{C}_{8} \mathrm{H}_{18}$ & 296.2 & 3.86 & 102.2 & 24.7 & 0.233 & 18.91 & 0.453 & " & -1.09 \\
\hline & $"$ & $\mathrm{C}_{8} \mathrm{H}_{6}$ & 288.5 & 3.76 & 118.3 & 47.7 & 0.304 & 24.21 & 0.410 & 0.422 & -2.84 \\
\hline & $"$ & $\mathrm{CCl}_{4}$ & 283.1 & 3.68 & 149.5 & 45.0 & 0.558 & 32.62 & 0.385 & 0.387 & -0.52 \\
\hline & $"$ & $\mathrm{CHCl}_{3}$ & 260 & 3.31 & 150.5 & 54.9 & 0.496 & 32.46 & 0.389 & $*$ & 0.52 \\
\hline & II b.I & $\mathrm{C}_{2} \mathrm{H}_{5} \mathrm{OH}$ & 243.1 & 4.08 & 126.9 & 63.1 & 0.28 & 23.03 & 0.462 & 0.454 & 1.76 \\
\hline & $"$ & $\mathrm{CH}_{3} \mathrm{OH}$ & 240 & 4.75 & 144.2 & 99 & 0.358 & 26.63 & 0.454 & $"$ & 0 \\
\hline & $"$ & $n-\mathrm{C}_{3} \mathrm{H}_{7} \mathrm{OH}$ & 263.7 & 4.01 & 118.8 & 49.95 & 0.273 & 22.30 & 0.447 & 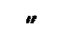 & -1.51 \\
\hline & II $\mathbf{b} \cdot \mathbf{2}$ & $\mathrm{CH}_{3} \mathrm{COCH}_{3}$ & 235 & 4.06 & 106.8 & 47 & 0.266 & 21.29 & 0.421 & 0.422 & -0.24 \\
\hline 5) & I a & $n-\mathrm{C}_{5} \mathrm{H}_{12}$ & 197 & 3.75 & $107.35 \mathrm{~s}$ & 33.0 & 0.232 & 18.75 & 0.480 & 0.480 & 0 \\
\hline 5) & II $\mathrm{c}$ & $n-\mathrm{C}_{6} \mathrm{H}_{14}$ & 234.8 & 3.82 & 112.053 & 29.6 & 0.234 & 18.84 & 0.499 & $"$ & 3.96 \\
\hline
\end{tabular}

\section{$\varphi$ は}

$$
\varphi=R T_{c} / P_{c} V_{c}=R T_{c} d_{c} \times 10^{3} / P_{c} M=1 / z_{c}
$$

$R=$ 気体定数 $=0.08205, z_{e}=$ 䠛界点火招りる王縮保数 よりるとめられる値である。

$z_{c}=P_{c} V_{e} / R T_{c}$ であるか⿰氵亏 $\varphi=1 / z_{e}$ (物性定数推算 法, p. 31)

$\varphi$ の平均值は $3.66^{* *}$ となるが, $\varphi>3.9$ のあのは水素 結合なとによって臨界状態で会合しているものとみなさ れる。 $K>0.5$ となっている気体杜すへて $\varphi>3.9$ のる のである。したがって $\varphi>3.9 て ゙ K>0.5$ となる場合 を会合㚳果とよふことにする。中には $\varphi>3.9$ です会合 猀果のあらわれないすのある(HCl，フセトンなど）。 一般炕 $t_{c}<190^{\circ} \mathrm{C}$ のガスで $\varphi>3.9$ のあのは会合効果 があらわれる(例外は $\mathrm{HCl}$ )。 $t_{0}>190^{\circ} \mathrm{C}$ のがスでは会 合粄果は原則的炕あらわれない(例外は $\mathrm{H}_{2} \mathrm{O}$ )。

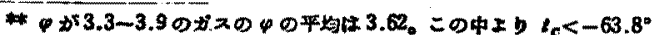

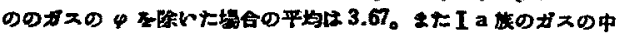

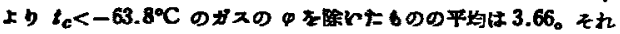
で汸3.66なとることにした。
Table \& Classification of gases by $t_{c}, \varphi$, and $K_{\text {obs, }}$ and formula applied to each gas group.

$$
\begin{aligned}
& \begin{array}{cccccc}
\begin{array}{c}
\text { group } \\
\text { of gases }
\end{array} & t_{0}^{\circ} & \varphi & K_{\text {obs }} & \text { effect } & \begin{array}{c}
\text { formula } \\
\text { applied }
\end{array}
\end{array} \\
& \text { a) } \mathrm{I} \mathrm{a}<190^{\circ} \mathrm{C}<3.9 \quad 00.48 \quad- \\
& \text { I c " } \quad 3.9<\quad 0.48 \text { association } \\
& \text { II a } \quad 190^{\circ} \mathrm{C}<\quad<3.9 \quad 0.385 \sim 0.465 \quad t_{c} \text { effect } \quad r \\
& \text { II } b_{1} \quad \text { " } 3.9<, \cong 0.45 \quad \text { " } \\
& \text { II } b_{1} \text { " " } \cong 0.42 \text { " " } \\
& \text { a) II c } \quad \pi \quad 0.5<\underset{\text { effect }}{\text { association }}
\end{aligned}
$$

a) I b $\left(\mathrm{HCl}_{1}\right)$, and II $c\left(\mathrm{H}_{2} \mathrm{O}\right)$ are exceptional cases

また $K$ が0.48より小さく0.38〜0.465 位火あらわ れるものは，いずれる臨界温度 $t_{c}$ が $190^{\circ} \mathrm{C}$ 以上のすの である。そこで $t_{c}>190^{\circ} \mathrm{C} て ゙, K<0.465$ となる場合 


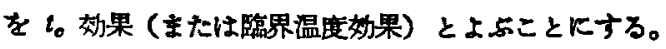

よってガスをます $t_{\mathrm{n}}\left\langle 190^{\circ} \mathrm{C}\right.$ と $t_{0}>190^{\circ} \mathrm{C}$ К分けて それぞれI族、版に分類し，次に山が 3.9 以下か以

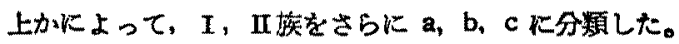
$t_{c}, \varphi$ および $K_{\text {obs }}$ K基つくがスの分類を Table 2 に示す。

a) I a, I b 族飞対する $K \quad$ I a, I b 族飞対しては $K$ は 0.48 附近となっている。この中で $K$ が 0.5 に近 い $\mathrm{HBr}$ と， $\mathrm{SO}_{2}$ を除いた場合の $K$ の平均は 0.480 と なる。また Table 1 の $K>0.45$ のすのの平均は 0.481 である。えこで $K=0.480$ をとると， $I_{a}, I_{b}$ 族のガス に対しては

$$
\begin{aligned}
a_{c}^{*} & =0.430 \times 1.192 \times 10^{-5}\left(P_{e}^{3} \cdot d_{r} \cdot M^{2}\right)^{1 / 8} \\
& =5.72 \times 10^{-6}\left(P_{q}^{3} \cdot d_{q} \cdot M^{2}\right)^{1 / 6 \cdots \text { c.g.s }}
\end{aligned}
$$

を使用守ることができる。

b) 会合勃果济する禣正 $\mathrm{Ic}$ 族 $\left(\mathrm{NH}_{9}, n-\mathrm{C}_{1} \mathrm{H}_{10}\right)$ $\Pi c$ 族 $\left(\mathrm{H}_{2} \mathrm{O}\right)$ のガスは $K>0.5$ となり会合效果があら われている。臨界状態で分子が会合状態にり，常医に なるとその会合がくずれるすのと考えられるガスに会合 奻果が括こるすのとす推定されるがこ北はあくまです 憶测であって本望的のことは不明である。会合炏果と極 性との間にも性っきりした結諭がでなかった。会合姃果 のあらわれるガスに対しては

$$
\mu_{c}^{*}=0.480(\varphi / 3.66)^{n}\left(P_{c}^{3} \cdot d_{a} \cdot M^{2}\right)^{1 / 8} \times 1.192 \times 10^{-5}
$$

を使用すれ社よいことが分った。この埸合

$$
K_{\text {obs }} / 0.480=(\varphi / 3.66)^{n}
$$

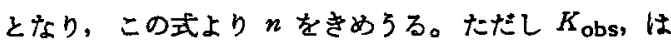
Table 1 にあたえてある（す）式による計算値である。 いま $\mathrm{NH}_{3}, \mathrm{H}_{2} \mathrm{O}, n-\mathrm{C}_{4} \mathrm{H}_{10}$ Kつい.て Table 1 の $K_{\text {obs }}$ の值を用い（8）式より $n$ を求めると， $n$ はそれ ぞれ $1.143 ， 1.047 ， 0.800$ となる。 $\varphi / 3.66$ が 1 に近い 值でむるから， $n=1$ としても喑差は $1.7 \%\left(\mathrm{NH}_{3}\right.$ 最大) 以下であるから，計算の便宜上 $n=1$ とする。すると

$$
\begin{aligned}
\mu_{c}^{*} & =0.480(\varphi / 3.66)\left(P_{c}^{3} \cdot d_{c} \cdot M^{2}\right)^{1 / 6} \times 1.192 \times 10^{-5} \\
& =5.72 \times 10^{-6}(\varphi / 3.66)\left(P_{c}{ }^{3} \cdot d_{g} \cdot M^{2}\right)^{3 / 6} \quad(B)
\end{aligned}
$$

を5る。すなわち会合效果のあらわれるガス（I， IIc 族）に対しては $\beta$ 式を使用することがでさる。

c) $\boldsymbol{t}_{\boldsymbol{c}}$ 效果をあらあすがスに姇する $\boldsymbol{K}$ 而a、 II $b_{1}$, II $b_{2}$ 族はいずれる $t_{c}>190^{\circ} \mathrm{C}$ であって $K$ は 0.48 上りかなり小さい値である。 $\varphi$ は 3.9 以上であって も以下であってす会合好果はあらわれない。 $K=0.88 \sim$ 0.465 Кでていて $K$ の一定值はえられない。現在のと ころ浅学のため, $t_{c}$ 好果に適当な補正を行って, 単一式

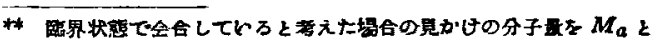

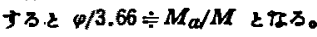

であらわすことはできない。Kの一踶は求められな いか，同族列とか，分子構造の類似した気体では，洼 $K$ が一定となっていることに注目される。たとえば正 アルコール類で性 $K=0.454 \mathrm{~K}$ 近く, $\mathrm{CCl}_{4}, \mathrm{CHCl}_{3} \tau$ は $K=0.887$ に近い。その他は $K=0.42 \sim 0.43$ であ る。分子構造の類似によって適当に $K$ をえらんで使用 する。

效果のあらわれるガス，すなわち 機ガスに対しては次式を使用する。

$$
\mu_{c}^{*}=K \times 1.192 \times 10^{-5}\left(P_{c}{ }^{3} \cdot d_{s} \cdot M^{2}\right)^{1 / 8}
$$

な怙 $\mathrm{C}_{\mathrm{G}} \mathrm{H}_{12}, \mathrm{C}_{6} \mathrm{H}_{14}$ の $\mu_{c}^{*}$ の実测値として化学便監以 外の数值》をとると、Table ] の終りに揭げたことき佔 となる。すなるち $n-\mathrm{C}_{6} \mathrm{H}_{12} の K=0.480, n-\mathrm{C}_{8} \mathrm{H}_{14}$ の $K=0.499$ となる。この場合 $t_{c}=197^{\circ} \mathrm{C}$ であが $\mathrm{C}_{5} \mathrm{H}_{3_{2}}$ は I a の中K, $\mathrm{C}_{8} \mathrm{H}_{14}$ は $\varphi=3.32$ であるが $K=0.499$ で相当大きく（普通は 0.42位のはずである）会合效果 があるるのとみなされ鳬のに入れなければならない。

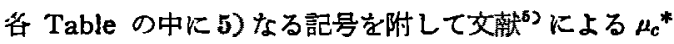
の計算值を示す。な持 $n-\mathrm{C}_{7} \mathrm{H}_{16}, n-\mathrm{C}_{8} \mathrm{H}_{18}$ の $\mu_{c}^{*}$ の実 測値は交献 ${ }^{82}$ によった。分類にあたって $t_{c}=190^{\circ} \mathrm{C}$, $\varphi=3 . の$ を区分点にとったが，これはあくまで現在まで の数值を基淮にした便宜的なるのにすきない。

d) $\alpha, \beta, \gamma$ 式の使用法 各ガス群に対して $\alpha, \beta, \gamma$ 式の中のとれを用いたらよいかを Table 2 に示してあ る。な Table 2 には $r$ 式使用すへき $K$ の値も示 しておる。

\section{§5, $\alpha, \beta, \gamma$ 式の棈度}

Table $1 K \alpha, \beta, r$ 式に使用すべき $K$ と，実際に 各気体の臨界值と $\mu_{c}^{*}$ の実測值, $\mu_{c}{ }^{*}$ (obs) を用いて( 式からるとめた $K$ の值， $K$ obs との比輍を示してある。 また Table 3 には $\alpha, \beta, \gamma$ 式による $\mu_{c}^{*}$ の計算值 $\mu_{c}^{*}$ (calc) と实測值 $\mu_{c}^{*}$ (obs) との比較定示してある。

Table 1, Table 3 より $\alpha, \beta, r$ 式の精度は次の通 りであることがわかる。

$a$ 式の誤差：多〈は $3 \%$ 以下 $\left(\mathrm{SO}_{2} 4.2 \%, \mathrm{HBr}\right.$ $3.98 \%$ ) で平均諆美注 $1.56 \%$

$\beta$ 式の祸差： $2 \%$ 以下

$\gamma$ 式の誤差：適当K $K$ をえらへばち\%以下。 $K=0.42 \sim 0.43$ としてい多くは $5 \%$ 以下で覀くても $10 \%$ をとえるとをは Isv.

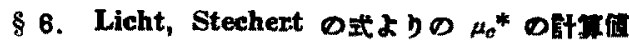

化学工学便譼 (昭和25. 丸善) p. 21 記載の LichtStechert の式で $T_{r}=1$ と捕いた場合の (2) 式によっ て $\mu_{c}^{*}$ を求めてみた。結果を Table 4 に示す。この式 
Table 3 Values of $\mu_{c}^{*}$ calculated by formulae, $\alpha, \beta, T$

$$
\mu_{o}^{*} \text { in } 10^{-6} \text { C. B. } 8 \text {. }
$$

\begin{tabular}{|c|c|c|c|c|c|c|c|c|c|c|c|}
\hline $\begin{array}{l}\text { group } \\
\text { of gas }\end{array}$ & gas & $\mu_{e}^{*}$ (obs) & $\mu_{c}^{*}$ (cale) & error & $\begin{array}{l}\text { formula } \\
\text { applied }\end{array}$ & $\begin{array}{l}\text { group } \\
\text { of gas }\end{array}$ & gas & $\mu_{c}^{*}$ (obs) & $\mu_{e}^{*}$ (calc) & $\begin{array}{c}\text { error } \\
\mathbf{x}\end{array}$ & $\begin{array}{l}\text { formula } \\
\text { applied }\end{array}$ \\
\hline I a & $\mathrm{CH}_{4}$ & 72.3 & 72.0 & -0.4 & $a$ & II $c$ & $\mathrm{H}_{2} \mathrm{O}$ & 226 & 224 & -0.9 & $"$ \\
\hline$"$ & $\mathrm{C}_{2} \mathrm{H}_{6}$ & 96.5 & 96.1 & -0.4 & $n$ & II a & $\mathrm{C}_{2} \mathrm{H}_{8} \mathrm{OC}_{2} \mathrm{H}_{8}$ & 103.5 & 101 & -2.4 & $\gamma$ \\
\hline$"$ & $\mathrm{C}_{3} \mathrm{H}_{0}$ & 103 & 102 & -1.0 & " & $"$ & ${ }_{n-}-\mathrm{C}_{6} \mathrm{H}_{12}$ & 95.2 & 94.4 & -0.8 & "r \\
\hline$"$ & $\mathrm{SO}_{3}$ & 189 & 181 & -4.2 & " & * & $n-\mathrm{C}_{0} \mathrm{H}_{14}$ & 94.6 & 94.8 & 0.2 & $"$ \\
\hline$"$ & $\mathrm{CO}_{3}$ & 150 & 152 & 1.3 & " & " & $n-C_{7} \mathrm{H}_{18}$ & 104 & 103 & -1.0 & $n$ \\
\hline$n$ & $\mathrm{Cl}_{2}$ & 186.5 & 188 & 0.8 & $"$ & " & $n-\mathrm{C}_{8} \mathrm{H}_{18}$ & 102 & 103 & 1.0 & $"$ \\
\hline$"$ & $\mathrm{~N}_{2} \mathrm{O}$ & 151 & 150 & -0.7 & $"$ & * & $\mathrm{C}_{6} \mathrm{H}_{6}$ & 118 & 121 & 2.5 & $"$ \\
\hline$"$ & $\begin{array}{l}\mathrm{Xe} \\
\mathrm{HBB}\end{array}$ & $\begin{array}{l}221 \\
227.6\end{array}$ & $\begin{array}{l}227 \\
219\end{array}$ & $\begin{array}{r}2.7 \\
-3.9\end{array}$ & $"$ & $"$ & $\mathrm{CCl}_{4}$ & 149.5 & 150 & 0.3 & $"$ \\
\hline “ & $\mathrm{C}_{2} \mathrm{H}_{2}$ & 107 & 104 & -2.8 & $"$ & " & $\mathrm{CHCl}_{3}$ & 150.5 & 150 & -0.3 & $*$ \\
\hline " & $\mathrm{C}_{2} \mathrm{H}_{4}$ & 97.3 & 95.9 & -1.4 & " & II $b_{\mathbf{l}}$ & $\mathrm{C}_{2} \mathrm{H}_{6} \mathrm{OH}$ & 127 & 125 & -1.6 & n \\
\hline$"$ & $\mathrm{CH}_{3} \mathrm{OCH}_{3}$ & 120 & 119 & -0.8 & $"$ & $"$ & $\mathrm{CH}_{3} \mathrm{OH}$ & 144 & 144 & 0 & $m$ \\
\hline$"$ & $\mathrm{CH}_{3} \mathrm{Cl}$ & 141.9 & 345.5 & 2.5 & . & " & $n-\mathrm{C}_{8} \mathrm{H}_{7} \mathrm{OH}$ & 119 & 121 & 1.7 & " \\
\hline I b & $\mathrm{HCl}$ & 158.7 & 159 & 0.3 & $"$ & II ba & $\mathrm{CH}_{3} \mathrm{COCH}_{3}$ & 107 & 107 & 0 & " \\
\hline $\begin{array}{l}\text { II c } \\
\text { " }\end{array}$ & $\begin{array}{l}\mathrm{NH}_{3} \\
x-\mathrm{C}_{8} \mathrm{H}_{10}\end{array}$ & $\begin{array}{l}139.6 \\
107\end{array}$ & $\begin{array}{l}137 \\
108\end{array}$ & $\begin{array}{r}-1.9 \\
0.9\end{array}$ & $\beta$ & $\begin{array}{l}\text { I a } \\
\text { I } c\end{array}$ & $\begin{array}{l}\text { 5) } n-C_{5} H_{12} \\
\text { 5) } n-C_{6} H_{14}\end{array}$ & $\begin{array}{l}107 \\
112\end{array}$ & $\begin{array}{l}107 \\
112.5\end{array}$ & $\begin{array}{l}0 \\
0.5\end{array}$ & $a$ \\
\hline
\end{tabular}

Table 4 Calculated values of $\mu_{c}^{*}$ by Licht-Stechert formula (2), Hirschfelder formula, Uyehara-Watson method, and by formula (1) and Uyebara-Watson method combinded. $\mu_{c}^{*}$ in $10^{-6}$ c.g.s.

\begin{tabular}{|c|c|c|c|c|c|c|c|c|c|c|c|}
\hline \multirow[b]{2}{*}{$\begin{array}{l}\text { group } \\
\text { of gases }\end{array}$} & \multirow{2}{*}{\multicolumn{2}{|c|}{ gas }} & \multirow[b]{2}{*}{$\begin{array}{c}\mu_{r *} \\
\text { observed }\end{array}$} & \multicolumn{2}{|c|}{ Licht-Stechert } & \multicolumn{2}{|c|}{ Hirschfelder } & \multirow{2}{*}{$\frac{\text { Uyehar }}{\text { Acalc) }_{\text {(calc }}^{*}}$} & \multirow{2}{*}{$\begin{array}{c}\text { Natson } \\
\text { errox } \\
x\end{array}$} & \multicolumn{2}{|c|}{$\begin{array}{l}\text { formula (1) and } \\
\text { Uyehara-Watson combined }\end{array}$} \\
\hline & & & & $\begin{array}{c}\mu_{0}^{*} \\
\text { (calc) }\end{array}$ & $\begin{array}{c}\text { error } \\
\%\end{array}$ & (cale) & error & & & (calc) & $\begin{array}{c}\text { error } \\
\times\end{array}$ \\
\hline I a & & $\mathrm{SO}_{2}$ & 189.1 & & & 196 & 3.7 & 183 & -3.3 & & \\
\hline$"$ & & $\mathrm{CO}_{2}$ & 150.3 & & & & & 153 & 1.6 & & \\
\hline n & & $\mathrm{Cl}_{3}$ & 186.5 & & & & & 187 & 0.3 & & \\
\hline$"$ & & $\mathrm{PH}_{\mathbf{g}}$ & 126.8 & & & & & 122 & -3.8 & & \\
\hline " & & $\mathrm{CH}_{4}$ & 72.3 & 74.7 & 3.3 & & & & & 73 & 1.0 \\
\hline " & & $\mathrm{C}_{2} \mathrm{H}_{6}$ & 96.5 & 98.9 & 2.5 & & & & & 96.8 & 0.3 \\
\hline " & & $\mathrm{C}_{3} \mathrm{H}_{8}$ & 102.7 & & & & & 104 & -1.4 & 102 & -0.6 \\
\hline$"$ & & i. $\mathrm{C}_{4} \mathrm{H}_{10}$ & 98.4 & & & 107 & 8.7 & 106 & 8.1 & & \\
\hline " & & $\mathrm{C}_{2} \mathrm{H}_{4}$ & 97.3 & 99.2 & 2.0 & 98 & 0.7 & 95.8 & -1.7 & 97 & -0.3 \\
\hline " & & $\mathrm{CH}_{3} \mathrm{Cl}$ & 141.9 & 148.5 & 4.7 & 152 & 7.1 & 150 & 6.0 & 145 & 2.3 \\
\hline I b & & $\mathrm{HCl}$ & 158.7 & 153 & -3.4 & 162 & 2.1 & 157 & -1.1 & 150 & -5.7 \\
\hline I c & & $\mathrm{NH}_{3}$ & 139.6 & 123 & -11.9 & 124 & -11.2 & 137 & -1.9 & 120 & -13.4 \\
\hline$"$ & & $n \cdot \mathrm{C}_{4} \mathrm{H}_{10}$ & 107.1 & 103 & -3.9 & 208 & 0.9 & 106 & -1.0 & 101 & -5.6 \\
\hline II $\mathrm{c}$ & & $\mathrm{H}_{\mathbf{2}} \mathrm{O}$ & 226.2 & 183 & -19.3 & 187 & -16.9 & 220 & -2.8 & 179 & -20.9 \\
\hline$"$ & & $\mathrm{CH}_{3} \mathrm{Cl}_{3}$ & 146.3 & & & 177 & 21.0 & & & & \\
\hline II $\mathbf{a}$ & & $n-\mathrm{C}_{6} \mathrm{H}_{12}$ & 95.2 & 110 & 15.3 & 108 & 13.4 & 106 & 11.4 & 107 & 12.4 \\
\hline i a & 5) & " & 107.3 & 110 & 2.8 & 108 & 0.7 & 106 & -1.2 & $20 ?$ & 0 \\
\hline II a & & $n-\mathrm{C}_{6} \mathrm{H}_{14}$ & 94.6 & 110 & 16.3 & 111 & 17.0 & 110 & 16.3 & 108 & 13.6 \\
\hline II $\mathrm{c}$ & 5) &. & 112.0 & 110 & -2.0 & 111 & -0.9 & 110 & -1.8 & 108 & -3.8 \\
\hline II a & & $n-C_{7} H_{16}$ & 103.9 & 110 & 5.8 & & & 113 & 8.8 & 108 & 3.5 \\
\hline$"$ & & $n-\mathrm{C}_{8} \mathrm{H}_{18}$ & 102.2 & 110 & 7.8 & 98 & -4.1 & $\mathbf{1 1 5}$ & 12.5 & 108 & 5.7 \\
\hline$"$ & & $\mathrm{C}_{3} \mathrm{H}_{5} \mathrm{OC}_{2} \mathrm{EX}_{6}$ & 108.5 & & & & & 419 & 15.0 & & \\
\hline " & & $\mathrm{C}_{6} \mathrm{H}_{6}$ & 118.3 & 146 & 23.7 & 142 & 20.0 & 139 & 17.5 & 143 & 21.4 \\
\hline " & & $\mathrm{CCl}_{4}$ & 149.5 & 191 & 27.8 & 180 & 20.4 & 184 & 23.1 & 187 & 25.3 \\
\hline " & & $\mathrm{CHCl}_{3}$ & 150.5 & 194 & 28.9 & 180 & 19.6 & 182 & 20.9 & 190 & 26.1 \\
\hline - & & $i-\mathrm{C}_{3} \mathrm{H}_{7} \mathrm{OH}$ & & & & & & 132 & 13.8 & & \\
\hline I $b_{1}$ & & $\mathrm{C}_{2} \mathrm{H}_{5} \mathrm{OH}$ & 126.9 & 133 & 4.7 & 150 & 18.2 & 148.5 & 17.0 & 130 & 2.5 \\
\hline 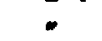 & & $\mathrm{CH}_{3} \mathrm{OH}$ & 144.2 & 150 & 4.2 & 169 & 17.2 & 167 & 15.8 & 147 & 1.9 \\
\hline " & & $m-C_{3} \mathrm{H}_{7} \mathrm{OH}$ & 118.8 & & & & & 132.5 & 11.5 & & \\
\hline E $b_{q}$ & & $\mathrm{CH}_{3} \mathrm{COCH}_{3}$ & 106.8 & 123 & 15.0 & & & 127 & 18.9 & 120.5 & 11.7 \\
\hline
\end{tabular}


のすつ欠点は 1) $R_{c}$ をすへてのガスについて一定とし て常效 3.5 の中に含ませている。2）会合奻果を考思し ていない。3） $t_{c}$ 动果を教していない。という点にあ る。1）の久点は $R_{e}$ の $1 / 6$ 莱が粘庭にひびいてくるか ら，てれ㤬と大きい誤差はあたえない。2）3）の久点の ために Table 4 よりみられるように，会合俗果のある ガス $\left(\mathrm{NH}_{3}, \mathrm{H}_{2} \mathrm{O}\right)$ ，および $t_{r}>190^{\circ} \mathrm{C}$ のガスに対して は著しい誤差が生している。（ただし正アルコール類で は誤差が大きくない。）よって（2）式恃会合效果のある ガス拉よび $t_{c}>190^{\circ} \mathrm{C}$ の有機ガスについてて使用しえ ないことがわかる。

\section{§ 7. Hirśchf elder の式による $\mu_{c}^{*}$ の計算值} 佐藤一雄氏の新著物性定数推算法"（昭和 29. 丸善, 以下文献》と称す) p. 87 の表 4.4および p. 88，89の 图 4.4、四4.5を用いて $\mathrm{NH}_{3}$ については p.90の (4.13a) 式, (4.13b) 式を 用いて表 4.4 の定数を計算した。結果を Table 4 K示 す。表よりみられることく会合效果の㻎しいガスや， $t_{c}$

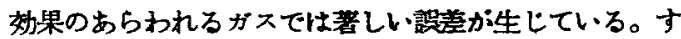
なわち Hirschfelder の式は, 会合好果のあらわれるか スや， $t_{c}>130^{\circ} \mathrm{C}$ の有就ガスに対しては使用しえないこ とが眀かとなった。

\section{\$8. Uyehara-Watson の方法による $\mu_{c}^{*}$ の計算檤}

文献》の p. 94 Кある Hougen-Watson の臨界粘度 の表4.5と p. 92 の图4.6の 的線图を用いて $\mu_{0}^{*} を$ 求めた。 また一方 Licht-Stechert の (1) 式より求めた $\mu_{c}$ を解い，交献》の p.92 の图 4.6Kよって $\mu_{c}^{*}$ を求 めてみた。これを Licht-Stechert そ Uyehara-Watson による方法とした。

結果を Table 4 に示す。Uyehara-Watson の方法て は，会合初果のあるガスに対しては赫正がなされていて 誤差が小さいことが特に注目される。しかし $t_{c}$ 効果に 対する補正はなされて和らす誤差が大きい。 $t_{c}>130^{\circ} \mathrm{C}$ の有機がスに対しては誤差が大きく使用し得ないことが 明かである。

Licht-Stechert の（1）式を Uyehara-Watson の方 法と結びつけた場合は，会合効果のあるガスに対しても また $t_{c}>190^{\circ} \mathrm{C}$ の有機ガスに対しても誤差が大きくて 使用しえない。（ただし正アルコール類には使用可能）

吿者の方法以外のどの方法によっても $t_{c}$ 效果のある ガスに対しては誤差が大きい。これは $\mu_{c}^{*}=\mu_{c} \cdot f\left(P_{r}\right)$ であらわされるが $\mu_{c}$ をあらわす推算式が有機ガスに対 して誤っているか，または有機ガスの $130^{\circ} \mathrm{C}$ 以上におい ては， $f(P r)$ が正しくないためてあろう。恐らく後者
の誤差が大きいためであろら。

\section{9. 括}

1. 常生の臨界温度に米ける気体の粘度 $\mu_{c}^{*}$ を古ら

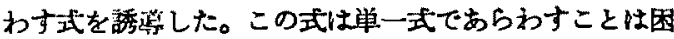

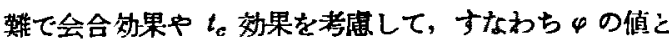
$\iota_{c}$ の偵を考虑して分類されたそれぞれの各ガス群汇通

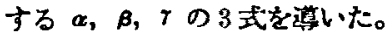

シ. $\alpha, \beta, r$ 式の使用法については Table 2 を参照 されたい。

3. Licht-Stechert ${ }^{13}$, Hirschfelder ${ }^{3)}$ の式, および Uyehara-Watson ${ }^{32,4)}$ の方法によっても $\mu_{c}^{*}$ を求めて みた。(Table 4)。この結果 a) Licht-Sthchert の式 ては会合狄果の生ずるガスおよび $t_{c}>190^{\circ} \mathrm{C}$ のガスて は大きい諟差が生じて使用できない。 b) Hirschfelder の式です会合好果のあるガス括よび $t_{c}>130^{\circ} \mathrm{C}$ の有機 ガスには使用できない。c) Uyehara-Watson の方涉は $t_{c}>130^{\circ} \mathrm{C}$ の有傤ガスには用いらいれな。といらことが 閌となった。

\section{Nomenclature}

c : Sutherland viscosity constant

$d_{c}:$ critical density $\left[\mathrm{g} / \mathrm{cm}^{3}\right]$

$K$ : constant for viscosity formula (5) $[-]$

$K_{c}$ : constant for viscosity formula (3) [ - ]

$M$ : gram molecular weight [g/mol]

$p_{c}:$ critical pressure [dynes $/ \mathrm{cm}^{2}$ ]

$\boldsymbol{P}_{c}$ : critical pressure [atm]

$R_{c}: R_{c}=P_{c} V_{c} / T_{c}$

$R$ : gas constant $0.08205 \quad\left[l \cdot \mathrm{atm} / \mathrm{mol}{ }^{\circ} \mathrm{K}\right]$

$t_{c}:$ critical temperature $\quad\left[{ }^{\circ} \mathrm{C}\right]$

$T_{c}:$ critical ternperature $\quad\left[{ }^{\circ} \mathrm{K}\right]$

$T_{r}: T / T_{c}$ reduced temperature $\quad[-]$

$V_{c}:$ critical volume $\quad[l / \mathrm{mol}]$

$\mu \quad$ : viscosity of gas at atmospheric pressure $[\mathrm{g} / \mathrm{cm} \cdot \mathrm{sec}]$

$\mu_{c}^{*}$ : viscosity of gas at critical temperature and atomospheric pressure [g/cm. $\mathrm{sec}]$

$\mu_{c}$ : viscosity at critical state $[\mathrm{g} / \mathrm{cm} \cdot \mathrm{sec}]$

$\varphi \quad: R T_{c} / P_{c} V_{c}=R \cdot T_{c} \cdot d_{c} \times 10^{3} / P_{c} \cdot M=1 / 2_{c}$

$P_{r}:$ reduced pressure $\quad$ [ $]$

$z_{c}$ : compressibility factor of gas at critical state $\quad[-]$

\section{Literature cited}

1) Licht, W., Stechert, D. G. Jr. : J. Phys. Chem., 40 23 (1944) 
2) Hirschfelder, J. O.: J. Chem. Phys., 16, 968 (1948, Chem. Reviews., 44, 222 (1949)

3) Uyehara, O. A., Watson, K. M.: Natl. Petrolezom News, Tech Sect., 36, R 764 (Oct. 4, 1944)

4) Hougen, O. A., Watson, K. M.: "Chemical Process
Principles." (John Wiley, 1947) p.870

5) Titani : But. Chem. Soc., Japan., \&, 255 (1933)

6) W. A. Hare, E. Mack: J. A. C. S., 54, 4272 (1932)

7) K. Sato: "Bussei Teisu Suisanhō" (Maruzen, 1954)

\section{Viscosity Formulae for Gases at Critical Temperature and Atmospheric Pressure}

\section{Hisashi Uchiyama}

Viscosity formulae for gases at critical temperature and atmospheric pressure are introduced in this paper. For the gases $\varphi>3.9$ and $t_{c}<190^{\circ} \mathrm{C}$, the constats $K$ in formula (5) are larger than 5.0. (the only exceptional case is for $\mathrm{HCl}$ ). This may be called "association effect." $\mathrm{H}_{2} \mathrm{O}$ vapor $\left(\varphi>3.9, t_{c}>190^{\circ} \mathrm{C}\right)$ also exhibits association effect. For the gases, $t_{c}>190^{\circ} \mathrm{C}$, the constants $K$ in formula ( 3 ) are smaller than 4.65 . This may be called " $t_{c}$ effect."

The viscosity formulae $\alpha, \beta$ and $\gamma$ were applied, as shown in Table 2.

In many cases, the errors of these formulae, $\alpha, \beta$ and $\gamma$ are respectively below $3 \%, 2 \%$ and $5 \%$ (Table 3).

$\mu_{c}{ }^{*}$ were also calculated by Licht-Stechert's formula, ${ }^{1)}$ Hirschfelder's formula? and Uyehara. Watson method.32,4) (Table 4).

Licht-Stechert's formula gave big errors for gases which exhibit association effect and for organic gases, $t_{e}$ of which $>190^{\circ} \mathrm{C}$.

Hirschfelder's formula could not be applied to the gases which exhibit association effect and to the organic gases, $t_{c}$ of which $>130^{\circ} \mathrm{C}$.

Uyehara-Watson method was in-applicable to organic gases, $t_{c}$ of which $>130^{\circ} \mathrm{C}$.

\section{Dorr そ Oliver}

“Chemical and Engineering News" の今年の Feb. 7 号の表柢は, New York の高層建筑を背景として向い あっている E. L. Oliver \& J. V. N. Dorr の二人によ ってかざられている。Dorr Co. z Oliver United Filters, Inc, そが合併して Dorr-Oliver といらーつの 新しい強力な粗㖪がで聿あがったのである。

John Van Nostrand Dorr は今年 83 歳，彼の化学技 術者としての経攵は 1888 年, 例の有名なニチッンの研 究所につとあにとをかはじまり，後に冾金関保の仕事 に移りそとで所部 Dorr 分科器を哞明して独立，その後 の発展ぶり汒よく知られている通りである。
一方今年 76 荿の Edwin Letts Oliver 頃これまた有名な F. G. Cottrell との交祭によって化学 一の眼を開かれ，前世紀末のゴールドラッシュの祭金山 で做いたが，やはり觓石処理を通じて洰遇器を铁明して 独立したのである。

2つの会社は 1981 年に部分的の合併在したが 2,3 年にして別れ，此度再ひ，しかも本格的な辟合を遂げた のである。Dorr 执び Oliver とい.5名に親しんでい

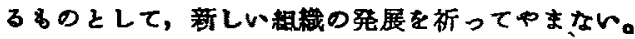

(H. R. T.) 